\title{
PEMODELAN INDEKS PEMBANGUNAN KESEHATAN MASYARAKAT KABUPATEN/KOTA DI PULAU KALIMANTAN MENGGUNAKAN PENDEKATAN REGRESI PROBIT
}

\author{
M. Fathurahman \\ Jurusan Matematika, Program Studi Statistika, Fakultas Matematika dan Ilmu Pengetahuan \\ Alam, Universitas Mulawarman \\ e-mail: fathur@fmipa.unmul.ac.id
}

\begin{abstract}
The Public Health Development Index (PHDI) is a composite indicator that describes the progress of health development and is useful for ranking provinces and districts/cities in achieving successful community health development. In addition, the PHDIM can also be used to determine regional priorities that require assistance in improving health development. Based on the publication of the PHDI ranking by the Health Research and Development Agency of the Ministry of Health in 2013, the PHDI ranking for 55 districts/cities in Kalimantan Island varied greatly. So it needs to be studied, examined the factors that influence it. The purpose of this study was to examine the modeling of the factors that influence the PHDI of districts/cities in Kalimantan Island in 2013 using the probit regression approach. The results of this study indicate that the factors that significantly influence the PHDI of districts/cities in Kalimantan Island in 2013 are the human development index and the labor force participation rate.
\end{abstract}

Keywords: Public Health Development Index, Categorical Data, Probit Regression

\begin{abstract}
Abstrak
Indeks Pembangunan Kesehatan Masyarakat (IPKM) merupakan indikator komposit yang menggambarkan kemajuan pembangunan kesehatan dan bermanfaat untuk menentukan peringkat provinsi dan kabupaten/kota dalam mencapai keberhasilan pembangunan kesehatan masyarakat. Selain itu IPKM dapat juga digunakan untuk menentukan prioritas daerah yang memerlukan bantuan dalam peningkatan pembangunan kesehatan. Berdasarkan publikasi peringkat IPKM oleh Badan Penelitian dan Pengembangan Kesehatan Kementerian Kesehatan tahun 2013 menunjukkan bahwa peringkat IPKM untuk 55 kabupaten/kota yang ada di Pulau Kalimantan sangat bervariasi. Sehingga perlu dikaji dikaji faktor-faktor yang mempengaruhinya. Tujuan dari penelitian ini adalah mengkaji pemodelan faktor-faktor yang berpengaruh terhadap IPKM kabupaten/kota di Pulau Kalimantan tahun 2013 menggunakan pendekatan regresi probit. Hasil penelitian ini menunjukkan bahwa faktor-faktor yang signifikan berpengaruh terhadap IPKM kabupaten/kota di Pulau Kalimantan tahun 2013 adalah indeks pembangunan manusia dan tingkat partisipasi angkatan kerja.
\end{abstract}

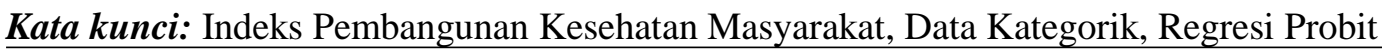




\section{PENDAHULUAN}

Mengacu pada program pembangunan kesehatan yang tertuang dalam UndangUndang Nomor 17 tahun 2007 tentang Rencana Pembangunan Jangka Panjang Nasional (RPJPN) tahun 2005-2025 dinyatakan bahwa dalam rangka mewujudkan sumber daya manusia yang berkualitas dan berdaya saing, maka kesehatan bersama-sama dengan pendidikan dan peningkatan daya beli masyarakat adalah tiga pilar utama untuk meningkatkan kualitas sumber daya manusia. Komposit dari tiga pilar utama ini selanjutnya dikenal dengan nama Indeks Pembangunan Manusia (IPM) [1].

Indikator kesehatan dalam IPM adalah Umur Harapan Hidup (UHH). UHH merupakan perkiraan lama hidup rata-rata penduduk dari sejak dilahirkan, dengan asumsi tidak ada perubahan pola mortalitas menurut umur. Namun muncul pertanyaan, apakah hanya cukup UHH yang panjang dapat mendukung pembangunan manusia? Diharapkan pembangunan manusia dari sektor kesehatan, selain mengupayakan agar penduduk dapat mencapai "umur hidup" yang panjang tetapi juga sehat berkualitas dan tidak bergantung pada orang lain. Selain itu, belum ada arah intervensi yang jelas khususnya di bidang kesehatan untuk meningkatkan UHH, sehingga diperlukan penjabaran yang lebih rinci dari indikator kesehatan yang terkait dengan UHH. Oleh karena itu, Badan Penelitian dan Pengembangan Kesehatan (Balitbangkes) Kementerian Kesehatan menyusun Indeks Pembangunan Kesehatan Masyarakat (IPKM).

IPKM merupakan kumpulan indikator kesehatan yang dapat dengan mudah dan langsung diukur untuk menggambarkan masalah kesehatan. Serangkaian indikator kesehatan ini secara langsung maupun tidak langsung dapat berperan meningkatkan UHH yang panjang dan sehat. UHH juga dapat dijadikan sebagai salah satu alat untuk mengevaluasi kinerja pemerintah pada keberhasilan pembangunan kesehatan serta sosial ekonomi di suatu wilayah, termasuk didalamnya derajat kesehatan [1].

Pada tahun 2013, Kementerian Kesehatan melalui Balitbangkes telah mempublikasikan peringkat IPKM untuk provinsi dan kabupaten/kota di seluruh Indonesia serta IPKM Indonesia. Semakin tinggi peringkat IPKM suatu provinsi atau kabupaten/kota, maka semakin baik kondisi kesehatan masyarakat di provinsi atau kabupaten/kota tersebut. Penelitian ini bertujuan mengkaji pemodelan faktor-faktor yang berpengaruh terhadap IPKM kabupaten/kota di Pulau Kalimantan tahun 2013 menggunakan pendekatan regresi probit. Pendekatan ini difokuskan untuk satu variabel dependen kualitatif (kategorik) yang mempunyai dua kategori dan dua atau lebih variabel independen kuantitatif.

Regresi probit ditemukan oleh Bliss pada tahun 1934. Menurut Bliss istilah "probit" pada regresi probit adalah singkatan dari "probability unit" sehingga dapat dikatakan bahwa regresi probit merupakan suatu model regresi yang berkaitan dengan unit-unit probabilitas [2].

Beberapa penelitian yang mengkaji regresi probit adalah [3] mengkaji pemilihan model regresi probit terbaik. [4] mengkaji variabel pengontrol hubungan antara variabel independen dan dependen pada regresi probit. [5] mengkaji pemodelan regresi probit dan penerapannya untuk data mining. [6] mengkaji pemodelan ketahanan pangan di Afrika dengan regresi probit. [7] dan [8] mengkaji pemodelan dan prediksi kebangkrutan bank di Slovakia dengan regresi probit. [9] mengkaji dan mengembangkan paket software R yang diberi nama SimCorMultRes untuk simulasi dan analisis regresi probit. [10] mengkaji pemodelan faktor-faktor yang berpengaruh terhadap penderita diabetes dan HIV/AIDS dengan regresi probit semiparametrik.

\section{METODE PENELITIAN}

Metodologi dalam artikel ini meliputi kajian pustaka untuk landasan teori dan metode penelitian untuk langkah-langkah analisis data.

\section{A. Indeks Pembangunan Kesehatan Masyarakat \\ Indeks Pembangunan Kesehatan} Masyarakat (IPKM) pertama kali disusun pada tahun 2010 dengan menggunakan data survei tahun 2007 dan 2008 yang disebut dengan IPKM 2007. Model IPKM 2007 menggunakan indikator yang ada pada data Riset Kesehatan Dasar (Riskesdas) 2007, hasil Survei Sosial 
Ekonomi Nasional (Susenas) 2007 dan Survei Potensi Desa (Podes) 2008. Model IPKM 2007 terdiri dari 24 indikator. Pemilihan indikator berdasarkan kesepakatan pakar bidang kesehatan. Model IPKM 2007 mempunyai keterbatasan indikator karena indikator kesehatan yang dianggap penting tidak tersedia di Riskesdas 2007. Hal ini disebabkan ide penyusunan IPKM muncul setelah Riskesdas 2007 selesai dilaksanakan. Berdasarkan hal tersebut, maka Riskesdas 2013 diupayakan dapat berperan menyempurnakan model IPKM 2007 dalam hal mengumpulkan indikator kesehatan yang lebih lengkap [1].

Melengkapi dan menyempurnakan indikator merupakan salah satu bagian dari pengembangan model IPKM 2013. Penjelasan mengenai hal-hal yang terkait dengan pengembangan IPKM 2013 adalah sebagai berikut [1]:

1. Penambahan indikator yang dianggap penting tetapi tidak dikumpulkan pada tahun 2007.

2. Pengurangan indikator yang dianggap pada saat ini kurang berperan terhadap perubahan status kesehatan.

3. Beberapa indikator dipertajam dengan menambahkan kriteria yang lebih sensitif untuk menjelaskan masalah kesehatan.

Proses pengembangan IPKM 2013 dilakukan melalui serangkaian pertemuan, baik internal Balitbangkes maupun lintas program, termasuk dengan para pakar dalam dan luar negeri. Dalam rangkaian kegiatan tersebut, menetapkan indikator, bobot, dan nilai minimum dan maksimum, yang digunakan dalam pengembangan IPKM 2013. Dasar pemilihan bersifat substansi kesehatan, pertimbangan prioritas program kesehatan dan rencana pembangunan nasional. Berdasarkan pertimbangan tersebut maka jumlah indikator kesehatan yang digunakan dalam IPKM 2013 sebanyak 30. Pengembangan model IPKM tahun 2013 bertujuan untuk memperkaya informasi indikator kesehatan sehingga dapat menghasilkan penajaman program yang harus diintervensi di kabupaten/kota. Pengembangan model IPKM 2013 juga mencakup perubahan metode penghitungan indeks. Metode ini mengelompokkan 30 indikator terpilih menjadi 7 kelompok indikator kesehatan yaitu kesehatan balita (6 indikator), kesehatan reproduksi (3 indikator), pelayanan kesehatan (5 indikator), perilaku kesehatan (5 indikator), penyakit tidak menular (6 indikator), penyakit menular (3 indikator) dan kesehatan lingkungan (2 indikator). Setiap indikator tersebut dihitung nilai sub indeksnya masing-masing. Hasil nilai sub indeks ini dapat memberikan gambaran baik buruknya kondisi kesehatan di tiap kabupaten/kota menurut masing-masing kelompok. Nilai indeks mendekati satu menunjukkan kondisi yang baik [1].

\section{B. Regresi Probit}

Regresi probit merupakan salah satu model regresi yang dapat menjelaskan hubungan antara variabel dependen kualitatif (kategorik) berdistribusi normal dan Bernoulli dan variabel independen kualitatif, kuantitatif, atau gabungan kualitatif dan kuantitatif.

Pemodelan regresi probit menggunakan fungsi penghubung (link function) distribusi normal dengan fungsi distribusi probabilitas dan fungsi distribusi kumulatif berturut-turut seperti persamaan (1) dan (2).

$$
\begin{aligned}
& f(y)=\frac{1}{\sqrt{2 \pi \sigma^{2}}} \exp \left[\left(\frac{y-\mu}{\sigma}\right)^{2}\right], \\
& \text { untuk }-\infty<y<\infty, \sigma^{2}>0 \\
& \begin{aligned}
P(Y \leq y) & =\Phi(y) \\
& =\int_{-\infty}^{y} \frac{1}{\sqrt{2 \pi \sigma^{2}}} \exp \left[\left(\frac{u-\mu}{\sigma}\right)^{2}\right] d u .
\end{aligned}
\end{aligned}
$$

Jika pada persamaan (1) $\mu=1$ dan $\sigma^{2}=0$, maka diperoleh distribusi normal standar dengan fungsi distribusi probabilitas dan fungsi distribusi kumulatif berturut-turut seperti persamaan (3) dan (4).

$$
\begin{aligned}
& \phi(t)=\frac{1}{\sqrt{2 \pi}} \exp \left(-\frac{1}{2} t^{2}\right),-\infty<t<\infty \\
& \begin{aligned}
P(Y \leq y)= & \Phi(t) \\
\quad & =\int_{-\infty}^{t} \frac{1}{\sqrt{2 \pi}} \exp \left(-\frac{1}{2} u^{2}\right) d u .
\end{aligned}
\end{aligned}
$$

Model regresi probit dapat ditulis seperti persamaan sebagai berikut [11]:

$\Phi^{-1}\left(\pi_{i}\right)=\boldsymbol{x}_{i}^{T} \boldsymbol{\beta}$, untuk $i=1,2, \ldots, n$

dimana $\boldsymbol{x}_{i}^{T}=\left(\begin{array}{lllll}1 & X_{1} & X_{2} & \cdots & X_{k}\end{array}\right)$ adalah vektor variabel independen pada pengamatan ke- $i, \boldsymbol{\beta}=\left(\begin{array}{lllll}\beta_{0} & \beta_{1} & \beta_{2} & \cdots & \beta_{k}\end{array}\right)^{T}$ adalah vektor parameter, $\Phi^{-1}\left(\pi_{i}\right)$ adalah probit link function dan $\pi_{i}=P\left(Y_{i}=y\right)$ adalah probabilitas variabel dependen pada pengamatan ke- $i$ mempunyai kategori $y$, 
untuk $y=0,1$ yang dinyatakan sebagai berikut:

$P\left(Y_{i}=1\right)=\Phi\left(\boldsymbol{x}_{i}^{T} \boldsymbol{\beta}\right), i=1,2, \ldots, n$

$P\left(Y_{i}=0\right)=1-\Phi\left(\boldsymbol{x}_{i}^{T} \boldsymbol{\beta}\right)$.

Taksiran parameter model regresi probit pada persamaan (5) dapat diperoleh dengan metode Maximum Likelihood Estimation (MLE). Estimasi parameter menggunakan metode ini diawali dengan menentukan fungsi likelihood dan fungsi log-likelihood sebagai berikut:

$$
\begin{aligned}
& L(\boldsymbol{\beta})=\prod_{i=1}^{n}\left[\left(\Phi\left(\boldsymbol{x}_{i}^{T} \boldsymbol{\beta}\right)\right)^{y_{i}}\left(1-\boldsymbol{x}_{i}^{T} \boldsymbol{\beta}\right)^{1-y_{i}}\right] \\
& Q=\ln L(\boldsymbol{\beta}) \\
& =\sum_{i=1}^{n}\left\{y_{i} \ln \left[\Phi\left(\boldsymbol{x}_{i}^{T} \boldsymbol{\beta}\right)\right]+\right. \\
& \left.\quad\left(1-y_{i}\right) \ln \left[1-\Phi\left(\boldsymbol{x}_{i}^{T} \boldsymbol{\beta}\right)\right]\right\} .
\end{aligned}
$$

Selanjutnya memaksimumkan fungsi loglikelihood dengan cara menentukan turunan parsial orde pertama fungsi log-likelihood terhadap parameter yang diestimasi kemudian disamakan dengan nol, yaitu

$\frac{\partial Q}{\partial \boldsymbol{\beta}}=\sum_{i=1}^{n}\left[\frac{q_{i} \phi\left(q_{i} \boldsymbol{x}_{i}^{T} \boldsymbol{\beta}\right)}{\Phi\left(q_{i} \boldsymbol{x}_{i}^{T} \boldsymbol{\beta}\right)}\right] \boldsymbol{x}_{i}=\sum_{i=1}^{n} \lambda_{i} \boldsymbol{x}_{i}=$

$\mathbf{0}$

dimana $\lambda_{i}=\frac{q_{i} \phi\left(q_{i} x_{i}^{T} \boldsymbol{\beta}\right)}{\Phi\left(q_{i} x_{i}^{T} \boldsymbol{\beta}\right)}$ dan $q_{i}=2 y_{i}-1$.

Berdasarkan persamaan (10), terlihat bahwa hasil turunan parsial pertama fungsi log-likelihood terhadap parameter yang ditaksir menghasilkan fungsi yang tidak closed form. Sehingga diperlukan pendekatan numerik untuk mendapatkan estimator parameter.

Salah satu pendekatan numerik yang dapat digunakan adalah metode Fisher Scoring. Metode ini membutuhkan turunan parsial kedua fungsi log-likelihood terhadap parameter yang diestimasi sebagai berikut:

$\frac{\partial^{2} Q}{\partial \boldsymbol{\beta} \partial \boldsymbol{\beta}^{T}}=-\sum_{i=1}^{n}-\lambda_{i}\left(\lambda_{i}+\boldsymbol{x}_{i}^{T} \boldsymbol{\beta}\right) \boldsymbol{x}_{i} \boldsymbol{x}_{i}^{T}$

dimana $\lambda_{i}$ seperti pada persamaan (10).

Persamaan yang digunakan untuk mendapatkan estimator parameter dengan metode Fisher Scoring adalah:

$\widehat{\boldsymbol{\beta}}_{(m+1)}=\widehat{\boldsymbol{\beta}}_{(m)}+\mathbf{I}^{-1}\left[\widehat{\boldsymbol{\beta}}_{(m)}\right] \mathbf{g}\left[\widehat{\boldsymbol{\beta}}_{(m)}\right]$,

untuk $m=1,2, \ldots$

dimana $\widehat{\boldsymbol{\beta}}$ adalah estimator parameter model regresi probit yaitu $\widehat{\boldsymbol{\beta}}=\left[\hat{\beta}_{0} \hat{\beta}_{1} \hat{\beta}_{2} \cdots \hat{\beta}_{k}\right]^{T}$. $\mathbf{I}^{-1}(\widehat{\boldsymbol{\beta}})$ adalah invers dari matriks informasi Fisher, yaitu
$\mathbf{I}^{-1}(\widehat{\boldsymbol{\beta}})=-E\left[\frac{\partial^{2} Q}{\partial \boldsymbol{\beta} \partial \boldsymbol{\beta}^{T}}\right]$

dengan $E\left[\frac{\partial^{2} Q}{\partial \boldsymbol{\beta} \partial \boldsymbol{\beta}^{T}}\right]$ adalah nilai ekspektasi dari turunan parsial orde kedua fungsi loglikelihood terhadap parameter yang diestimasi dan $\frac{\partial^{2} Q}{\partial \boldsymbol{\beta} \partial \boldsymbol{\beta}^{T}}$ seperti pada persamaan (11). $\mathbf{g}(\widehat{\boldsymbol{\beta}})$ adalah vektor gradien dengan elemenelemennya adalah turunan parsial orde pertama fungsi log-likelihood terhadap parameter yang diestimasi, $\mathbf{g}(\widehat{\boldsymbol{\beta}})=\left[\frac{\partial Q}{\partial \boldsymbol{\beta}}\right]^{T}$ dengan $\frac{\partial Q}{\partial \boldsymbol{\beta}}$ seperti pada persamaan (10).

Proses iterasi Fisher Scoring untuk parameter $\boldsymbol{\beta}$ berhenti jika terpenuhi kondisi konvergen, yaitu $\left\|\widehat{\boldsymbol{\beta}}_{(m+1)}-\widehat{\boldsymbol{\beta}}_{(m)}\right\| \leq \epsilon$, untuk $\epsilon$ adalah bilangan positif yang sangat kecil. Hasil estimasi yang diperoleh adalah $\widehat{\boldsymbol{\beta}}_{(m+1)}$ pada saat iterasi terakhir.

Berdasarkan matriks Informasi Fisher pada persamaan (12) dapat diperoleh taksiran untuk matriks varians kovarians dari parameter $\boldsymbol{\beta}$, yaitu $\operatorname{Cov}(\widehat{\boldsymbol{\beta}})=\mathbf{I}^{-1}(\widehat{\boldsymbol{\beta}})$.

Setelah dilakukan estimasi parameter model regresi probit dilanjutkan dengan pengujian hipotesis parameter. Pengujian ini meliputi uji simultan dan uji parsial. Hipotesis yang digunakan untuk uji simultan diformulasikan sebagai berikut:

$H_{0}: \beta_{1}=\beta_{2}=\cdots=\beta_{k}=0$

$H_{1}$ : Minimal terdapat satu $\beta_{j} \neq 0$, untuk

$$
j=1,2, \ldots, k .
$$

Statistik uji untuk uji simultan adalah statistik likelihood ratio yang dapat diperoleh dengan metode Likelihood Ratio Test (LRT) [11]:

$G^{2}=-2[\mathcal{L}(\widehat{\omega})-\mathcal{L}(\widehat{\Omega})]$

dimana $\quad \mathcal{L}(\widehat{\omega})=\ln L(\widehat{\omega}) \quad$ adalah nilai maksimum fungsi log-likelihood dibawah $H_{0}$ dan $\mathcal{L}(\widehat{\Omega})=\ln L(\widehat{\Omega})$ adalah nilai maksimum fungsi log-likelihood dibawah populasi.

Statistik uji pada persamaan (13) secara asimtotik berdistribusi chi-square dengan derajat bebasnya adalah banyaknya parameter model dibawah populasi dikurangi dengan banyaknya parameter model dibawah $H_{0}$, yaitu $v=(k+1)-1=k$. Daerah kritis untuk uji simultan adalah $H_{0}$ ditolak jika nilai $G^{2}>$ $\chi_{(\alpha, v)}^{2}$ atau nilai probabilitas $(P)<\alpha$, dimana 
$\alpha$ adalah tingkat signifikansi dan nilai $\chi_{(\alpha, v)}^{2}$ dapat diperoleh dari tabel distribusi chi-square.

Setelah dilakukan uji simultan, pengujian hipotesis parameter selanjutnya adalah uji parsial. Hipotesis untuk uji parsial diformulasikan sebagai berikut:

$H_{0}: \beta_{j}=0$

$H_{1}: \beta_{j} \neq 0$, untuk $j=1,2, \ldots, k$.

Statistik uji yang digunakan untuk uji ini adalah statistik Wald [11]:

$$
Z_{j}=\frac{\widehat{\beta}_{j}}{\widehat{S E}\left(\widehat{\beta}_{j}\right)}
$$

dimana $\hat{\beta}_{j}$ adalah estimator parameter model dan $\widehat{S E}\left(\hat{\beta}_{j}\right)$ adalah standar error dari estimator parameter model.

Statistik Wald pada persamaan (14) secara asimtotik berdistribusi normal standar. Daerah kritis untuk uji parsial adalah $H_{0}$ ditolak jika nilai $\left|Z_{j}\right|>Z_{\alpha / 2}$ atau nilai $P$ kurang dari $\alpha$, dimana $\alpha$ adalah tingkat signifikansi dan nilai $Z_{\alpha / 2}$ dapat diperoleh dari tabel distribusi normal standar.

\section{Metode Penelitian}

Data yang digunakan dalam penelitian ini merupakan data sekunder yang diperoleh dari Badan Penelitian dan Pengembangan (Balitbangkes) Kementerian Kesehatan dan Badan Pusat Statistik (BPS). Data yang diambil dari Balitbangkes Kementerian Kesehatan adalah data IPKM untuk variabel dependen (Y) dengan kategori 0 = IPKM < Cut-off dan IPKM $\geq$ Cut-off, dimana Cut-off adalah nilai IPKM Indonesia tahun 2013 sebesar 0,5404 [1]. Sedangkan data yang diambil dari BPS adalah data untuk variabel independen yang meliputi IPM $\left(X_{1}\right)$, persentase penduduk miskin $\left(X_{2}\right)$, pertumbuhan ekonomi $\left(X_{3}\right)$, tingkat pengangguran terbuka (TPT) $\left(X_{4}\right)$, kontribusi terhadap jumlah Produk Domestik Regional Bruto (PDRB) provinsi $\left(X_{5}\right)$, dan tingkat partisipasi angkatan kerja (TPAK) $\left(X_{6}\right)$.

Teknik pengambilan sampel yang digunakan dalam penelitian ini adalah pengambilan sampel jenuh, yaitu besar ukuran sampel sama dengan populasi. Sampel yang digunakan sebanyak 55 kabupaten/kota di Pulau Kalimantan tahun 2013, yang terdiri atas 46 kabupaten dan 9 kota.

Teknik analisis data untuk pemodelan IPKM kabupaten/kota di Pulau Kalimantan tahun 2013 menggunakan pendekatan regresi probit adalah sebagai berikut :

1. Melakukan analisis statistik deskriptif terhadap variabel penelitian.

2. Melakukan uji multikolinieritas terhadap variabel independen.

3. Melakukan estimasi parameter model regresi probit dengan metode maximum likelihood dan Fisher Scoring.

4. Melakukan pengujian hipotesis parameter secara serentak dan parsial berturut-turut dengan metode LRT dan uji Wald.

5. Mendapatkan variabel independen yang signifikan berpengaruh terhadap variabel dependen.

Pengolahan dan analisis data untuk estimasi dan pengujian hipotesis parameter menggunakan software R untuk windows versi 3.5.2.

\section{HASIL DAN PEMBAHASAN}

Pemodelan IPKM kabupaten/kota di Pulau Kalimantan tahun 2013 menggunakan pendekatan regresi probit diawali dengan deskripsi dari variabel penelitian. Deskripsi dari variabel dependen dan independen disajikan pada Tabel 1 dan Tabel 2 .

Tabel 1. Deskripsi Variabel Dependen

\begin{tabular}{|l|c|c|}
\hline \multicolumn{1}{|c|}{ IPKM } & Frekuensi & Persentase \\
\hline $\begin{array}{l}\text { IPKM }<\text { Cut- } \\
\text { off }\end{array}$ & 39 & 70,9 \\
\hline $\begin{array}{l}\text { IPKM } \geq \text { Cut- } \\
\text { off }\end{array}$ & 16 & 29,1 \\
\hline \multicolumn{1}{|c|}{ Jumlah } & 55 & 100 \\
\hline
\end{tabular}

Berdasarkan Tabel 1, terlihat bahwa terdapat 39 kabupaten/kota $(70,9 \%)$ yang mempunyai IPKM kurang dari Cut-off. Sedangkan kabupaten/kota yang mempunyai IPKM lebih dari Cut-off sebanyak 16 kabupaten/kota $(29,1 \%)$.

Tabel 2. Deskripsi Variabel Independen

\begin{tabular}{|c|c|c|c|c|}
\hline Variabel & Min & Max & Mean & SD \\
\hline$X_{1}$ & 66,81 & 79,87 & 73,19 & 3,08 \\
\hline$X_{2}$ & 2,48 & 14,18 & 7,14 & 2,67 \\
\hline$X_{3}$ & 0,7 & 9,03 & 6,1 & 1,32 \\
\hline$X_{4}$ & 0,78 & 11,19 & 4,65 & 2,69 \\
\hline
\end{tabular}




\begin{tabular}{|c|c|c|c|c|}
\hline$X_{5}$ & 1,34 & 32,39 & 9,1 & 6,1 \\
\hline$X_{6}$ & 56,98 & 77,58 & 68,78 & 5,7 \\
\hline
\end{tabular}

Berdasarkan Tabel 2, terlihat bahwa ratarata IPM kabupaten/kota di Pulau Kalimantan tahun 2013 adalah sebesar 73,19 dengan standar deviasi sebesar 3,08. IPM terendah sebesar 66,81 dan tertinggi sebesar 79,87. Rata-rata persentase penduduk miskin kabupaten/kota di Pulau Kalimantan tahun 2013 adalah sebesar 7,14 persen dengan standar deviasi sebesar 2,67 persen. Persentase penduduk miskin terendah sebesar 2,48 persen dan tertinggi sebesar 14,18 persen. Rata-rata pertumbuhan ekonomi kabupaten/kota di Pulau Kalimantan tahun 2013 adalah sebesar 6,1 persen dengan standar deviasi sebesar 1,32 persen. Pertumbuhan ekonomi terendah sebesar 0,7 persen dan tertinggi sebesar 9,03 persen. Rata-rata TPT kabupaten/kota di Pulau Kalimantan tahun 2013 adalah sebesar 4,64 persen dengan standar deviasi sebesar 2,69 persen. TPT terendah sebesar 0,78 persen dan tertinggi sebesar 11,19 persen. Rata-rata kontribusi kabupaten/kota di Pulau Kalimantan tahun 2013 terhadap jumlah PDRB provinsi adalah sebesar 9,1 persen dengan standar deviasi sebesar 6,1 persen. Kontribusi kabupaten/kota terhadap jumlah PDRB provinsi terendah sebesar 1,34 persen dan tertinggi sebesar 32,39 persen. Rata-rata TPAK kabupaten/kota di Pulau Kalimantan tahun 2013 adalah sebesar 68,78 persen dengan standar deviasi sebesar 5,7 persen. TPAK terendah sebesar 56,98 persen dan tertinggi sebesar 77,58 persen.

Pembahasan selanjutnya adalah pengujian asumsi multikolinieritas. Untuk mengetahui adanya multikolinieritas dapat digunakan kriteria nilai variance inflation factor (VIF). Jika nilai VIF untuk setiap variabel independen lebih dari 10, maka terdapat multikolinieritas [12]. Hasil nilai VIF untuk setiap variabel independen disajikan pada Tabel 3.

Tabel 3 Nilai VIF Variabel Independen

\begin{tabular}{|c|c|}
\hline Variabel & Nilai VIF \\
\hline$X_{1}$ & 1,78 \\
\hline$X_{2}$ & 1,21 \\
\hline$X_{3}$ & 1,21 \\
\hline$X_{4}$ & 1,6 \\
\hline$X_{5}$ & 1,55 \\
\hline$X_{6}$ & 1,57 \\
\hline
\end{tabular}

Hasil nilai VIF untuk setiap variabel independen yang terdapat pada Tabel 3 kurang dari 10. Hal ini menunjukkan bahwa tidak terdapat multikolinieritas antar variabel independen, sehingga semua variabel independen dapat digunakan untuk pemodelan IPKM kabupaten/kota di Pulau Kalimantan tahun 2013.

Tahapan awal pemodelan IPKM kabupaten/kota di Pulau Kalimantan tahun 2013 dengan pendekatan regresi probit adalah menentukan estimator parameter model regresi probit dengan metode MLE dan Fisher Scoring berdasarkan persamaan (12). Hasil estimasi dan uji parsial parameter yang diperoleh melalui perhitungan dengan software R disajikan pada Tabel 4.

Tabel 4. Estimasi Parameter dan Nilai Statistik Uji Parsial

\begin{tabular}{|c|c|c|c|c|}
\hline Par & Est & Se & $\mathrm{Z}$ & $\mathrm{P}$ \\
\hline$\beta_{0}$ & $-5,997$ & 10,113 & $-0,593$ & 0,553 \\
\hline$\beta_{1}$ & 0,296 & 0,136 & 2,177 & $0,029^{*}$ \\
\hline$\beta_{2}$ & 0,096 & 0,124 & 0,774 & 0,439 \\
\hline$\beta_{3}$ & $-0,301$ & 0,211 & $-1,425$ & 0,154 \\
\hline$\beta_{4}$ & $-0,111$ & 0,121 & $-0,920$ & 0,357 \\
\hline$\beta_{5}$ & $-0,034$ & 0,042 & $-0,821$ & 0,412 \\
\hline$\beta_{6}$ & $-0,214$ & 0,069 & $-3,099$ & $0,002^{*}$ \\
\hline
\end{tabular}

*) Signifikan pada $\alpha=0,05$.

Setelah didapatkan estimator parameter model regresi probit pada Tabel 4 dilakukan uji simultan dan uji parsial terhadap parameter model regresi probit. Hipotesis untuk uji simultan diformulasikan sebagai berikut:

$H_{0}: \beta_{1}=\beta_{2}=\cdots=\beta_{6}=0$

$H_{1}$ : minimal terdapat satu $\beta_{j} \neq 0, j$

$$
=1,2, \ldots, 6
$$

Berdasarkan statistik uji likelihood ratio pada persamaan (13) dan hasil perhitungan dengan software $\mathrm{R}$, diperoleh nilai statistik uji $G^{2}$ sebesar 32,875 lebih dari nilai tabel chi-square sebesar 12,592 , sehingga $H_{0}$ ditolak. Hal ini menunjukkan bahwa diantara faktor-faktor IPM, persentase penduduk miskin, pertumbuhan ekonomi, TPT, kontribusi terhadap jumlah PDRB provinsi dan TPAK terdapat minimal satu faktor yang berpengaruh signifikan terhadap IPKM kabupaten/kota di Pulau Kalimantan tahun 2013.

Untuk mendapatkan faktor-faktor yang berpengaruh signifikan terhadap IPKM kabupaten/kota di Pulau Kalimantan tahun 2013 pada uji simultan dilakukan uji parsial. 
Hipotesis untuk uji ini diformulasikan sebagai berikut:

$H_{0}: \beta_{j}=0$

$H_{1}: \beta_{j} \neq 0$, untuk $j=1,2, \ldots, 6$.

Berdasarkan statistik uji pada persamaan (14) dan Tabel 4, terlihat bahwa faktor-faktor yang berpengaruh signifikan terhadap IPKM kabupaten/kota di Pulau Kalimantan tahun 2013 adalah IPM dan TPAK. Hal ini ditunjukkan oleh nilai statistik Wald untuk IPM sebesar 2,177 lebih dari nilai tabel distribusi normal standar sebesar 1,96 dan nilai statistik Wald untuk TPAK sebesar 3,099 kurang dari nilai tabel distribusi normal standar sebesar $-1,96$. Selanjutnya nilai $\mathrm{P}$ untuk IPM sebesar 0,029 dan TPAK sebesar 0,002 kurang dari nilai tingkat signifikansi sebesar 0,05 .

\section{KESIMPULAN DAN SARAN}

Berdasarkan hasil dan pembahasan, dapat disimpulkan bahwa faktor-faktor yang berpengaruh signifikan terhadap IPKM kabupaten/kota di Pulau Kalimantan tahun 2013 berdasarkan pemodelan dengan regresi probit adalah IPM dan TPAK. Sedangkan persentase penduduk miskin, pertumbuhan ekonomi, tingkat pengangguran terbuka, dan kontribusi terhadap jumlah PDRB provinsi tidak berpengaruh terhadap IPKM kabupaten/kota di Pulau Kalimantan tahun 2013.

Saran yang diajukan dari penelitian ini adalah pemodelan IPKM kabupaten/kota di Pulau Kalimantan menggunakan pendekatan regresi probit masih perlu dilakukan untuk penelitian selanjutnya. Hal ini dikarenakan keterbatasan data sekunder yang ada dalam penelitian ini terutama faktor-faktor lain yang diduga berpengaruh terhadap IPKM. Untuk mendapatkan estimator MLE untuk parameter model regresi probit pada penelitian selanjutnya dapat menggunakan pendekatan numerik yang lain, yaitu metode NewtonRaphson atau Quasi-Newton.

\section{DAFTAR PUSTAKA/REFERENSI}

[1] Badan Penelitian dan Pengembangan Kesehatan Kementerian Kesehatan 2014. "Indeks Pembangunan Kesehatan Masyarakat”, Jakarta.
[2] D. J. Finney 1971. "Probit Analysis", Third Edition, Cambridge University Press, Cambridge MA.

[3] G. Chen and H. Tsurumi, "Probit and Logit Selection" Communications in Statistics-Theory and Methods, Vol. 40, 2011, pp. 159-175.

[4] K. B. Karlson, A. Holm and R. Breen, "Comparing Regression Coefficients Between Same-sample Nested Models Using Logit and Probit: A New Method" Sociological Methodology, Vol. 42, 2012, pp. 286-313.

[5] M. Razzaghi, "The Probit Link Function in Generalized Linear Models for Data Mining Applications" Journal of Modern Applied Statistical Methods, Vol. 12, No. 1, May 2013, pp. 164-169.

[6] A. Abdulai and W. Huffman, "The Adoption and Impact of Soil and Water Conservation Technology: An Endogenous Switching Regression Application" Land Economics, Vol. 90, No. 1, 2014, pp. 26-43.

[7] T. Kliestik, K. Kocisova and $M$. Misankova "Logit and Probit Model used For Prediction of Financial Health of Company" Procedia Economics and Finance, Vol. 23, 2015, pp. 850-855.

[8] M. Kovacova and T. Kliestik, "Logit and Probit Application for the Prediction of Bankruptcy in Slovak Companies" Equilibrium. Quarterly Journal of Economics and Economic Policy, Vol. 12, Issue 4, December 2017, pp. 775-791.

[9] A. Touloumis, "Simulating Correlated Binary and Multinomial Responses under Marginal Model Specification: The SimCorMultRes Package" The R Journal, Vol. 8, No. 2, December 2016, pp. 79-91.

[10] H. Liu and J. Qin, "Semiparametric Probit Models with Univariate and Bivariate Current-Status Data" Biometrics, Vol. 74, March 2018, pp. 68-76.

[11] W. H. Greene 2003. "Econometric Analysis", Fifth Edition, Prentice Hall, New Jersey.

[12] M. H. Kutner, C. J. Nachtsheim and J. Neter 2004. "Applied Linear 
Pemodelan Indeks Pembangunan Kesehatan Masyarakat Kabupaten/Kota

di Pulau Kalimantan Menggunakan Pendekatan Regresi Probit

M. Fathurahman

Regression Models", Fourth Edition,

McGraw-Hill, New York. 